\title{
Desain dan Implementasi Current-Controlled Voltage Source Inverter untuk Kontrol Tegangan dan Frekuensi Generator Induksi Tiga Fasa
}

\author{
Resa Hidayat Pramasdeka, Dedet Candra Riawan dan Mochamad Ashari \\ Jurusan Teknik Elektro, Fakultas Teknologi Industri, Institut Teknologi Sepuluh Nopember (ITS) \\ J1. Arief Rahman Hakim, Surabaya 60111 \\ e-mail:dedet@ee.its.ac.id; ashari@ee.its.ac.id
}

\begin{abstract}
Abstrak-Mesin induksi dapat menghasilkan daya saat kecepatannya di atas kecepatan sinkron, bisa disebut juga sebagai generator induksi. Mesin induksi memiliki kelebihan yaitu konstruksinya yang simpel, level short-circuit yang rendah, perawatan yang mudah, dan harganya lebih murah. Dari semua kelebihan tersebut, mesin induksi juga memiliki kekurangan saat difungsikan sebagai generator yaitu karakteristik regulasi tegangan dan frekuensi yang tidak memuaskan serta membutuhkan daya reaktif untuk menjaga eksitasi. Perlu diketahui bahwa generator induksi tidak menghasilkan daya reaktif, tetapi membutuhkan daya reaktif dari luar. Untuk mengatasi masalah di atas, digunakanlah elektronika daya dengan menerapkan metode CurrentControlled pada Voltage Source Inverter (CC-VSI) sebagai pengontrol tegangan dan frekuensi output dari generator serta menyediakan daya reaktif untuk beban pada sisi AC. Sistem tersebut diperoleh dengan memberikan sinyal Sinusoidal Pulse Width Modulation (SPWM) ke IGBT/MOSFET pada inverter untuk pensaklaran. Dengan adanya CC-VSI, eksitasi yang dibutuhkan mesin dapat terpenuhi serta frekuensi, tegangan, dan aliran daya dapat dikontrol.
\end{abstract}

Kata Kunci-Generator induksi, current-controlled, voltage source inverter, sinusoidal pulse width modulation

\section{PENDAHULUAN}

$\mathrm{M}$ ARAKNYA pemanfaatan energi terbarukan (renewable energy) menjadi sebuah tantangan tersendiri demi kemajuan konsumsi energi dunia. Pembangkitan listrik menggunakan energi terbarukan merupakan sumber energi yang bersih dan dapat digunakan secara terus-menerus. Indonesia memiliki banyak potensi sumber energi terbarukan yang dapat dimanfaatkan untuk menambah kapasitas energi listrik sehingga dapat memasok energi ke konsumen yang semakin lama semakin bertambah. Karena penyebaran listrik yang belum merata, daerah yang terpencil bisa memanfaatkan sumber energi terbarukan sebagai pembangkit stand-alone.

Sumber energi terbarukan yang biasanya terletak di daerah terpencil di mana pasokan utilitas tidak tersedia atau sering terputus, sehingga sering menempatkan sumber energi dengan sistem stand-alone untuk memasok beban. Sumber energi tersebut dapat berupa air, angin, cahaya matahari, dan lain sebagainya. Situasi seperti ini mengharuskan sistem pembangkit listrik energi terbarukan melakukan regulasi tegangan agar kualitas daya yang dihasilkan dapat digunakan dengan baik [1]. Dalam pembangkitan energi terbarukan generator induksi lebih sering digunakan karena lebih cocok dengan digunakan pada kecepatan yang berubah-ubah dan perawatannya yang mudah. Masalah yang ada pada sistem stand-alone adalah pada keefektifan konsumsi dayanya, karena penggunaan beban akan berubah tergantung dari waktu ataupun keadaan. Karena itu diperlukan sebuah sistem agar kontinuitas daya dapat terjaga.

Salah satu contoh pada aplikasi sistem stand-alone seperti topologi di bawah [2]:

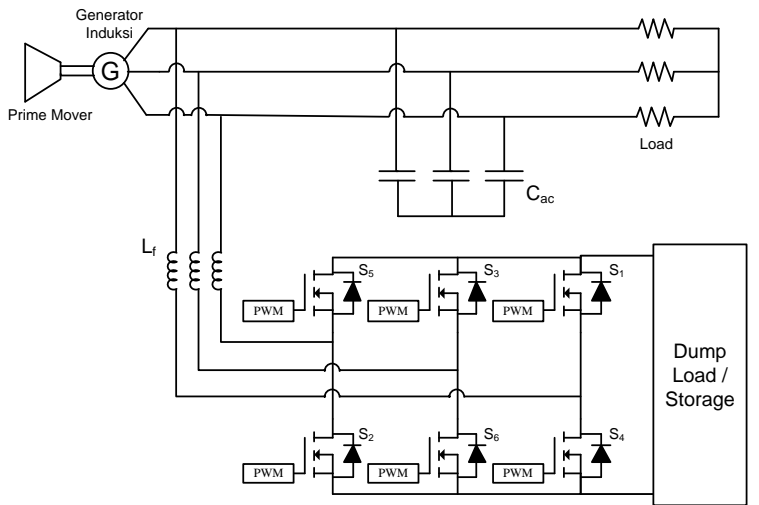

Gambar 1. Topologi Sistem Stand-Alone dengan Kecepatan Tetap

Pada sistem pembangkitan listrik, generator dikopel oleh prime mover dari turbin sehingga dapat menghasilkan daya. Kemudian output generator induksi disambungkan ke sebuah converter tiga fasa. Fungsi dari konverter ini adalah mengkonversikan AC (Alternating Current) ke DC (Direct Current) yang kemudian arus tersebut akan disimpan ke dalam baterai. VSI memiliki tiga fungsi penting dalam sistem yaitu:

a) Menetapkan frekuensi generator induksi agar konstan

b) Memberikan mekanisme regulasi tegangan sistem

c) Mengganti daya reaktif yang dibutuhkan generator induksi dan beban $\mathrm{AC}$

Beban pada bagian DC bisa berupa resistor untuk membuang daya berlebih atau berupa baterai. Dengan menggunakan beterai, daya berlebih yang dihasilkan generator bisa disimpan dan dapat digunakan untuk penambah daya saat dalam kondisi kelebihan beban [1].

\section{URAIAN PENELITIAN}

\section{A. Voltage Source Inverter (VSI) 3 Fasa}

VSI satu fasa mencakup aplikasi pada daya rendah dan VSI tiga fasa mencakup aplikasi pada daya menengah dan daya tinggi. Tujuan utama dari topologi ini adalah untuk menyediakan sumber tegangan tiga fasa dimana amplitudo, fase, dan frekuensi dari tegangan selalu dapat dikontrol [4]. Topologi standar dari VSI tiga fasa dapat dilihat pada Gambar 2. 


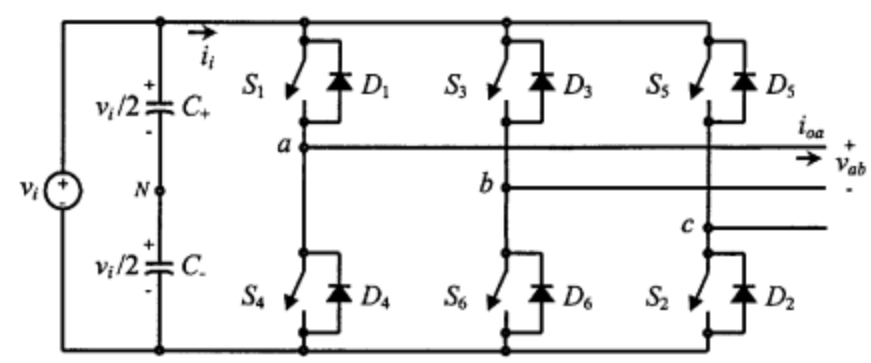

Gambar 2. Topologi VSI 3 fasa [4]

Rangkaian VSI terdiri dari enam saklar, dimana saklar tersebut dapat berupa BJT (Bipolar Junction Transistor), FET (Field Effect Transistor), atau IGBT (Insulated Gate Bipolar Transistor). Masing-masing saklar memiliki karakteristik yang berbeda, BJT dikendalikan menggunakan aliran arus sedangkan FET dan IGBT dikendalikan menggunakan tegangan. Inputnya dapat berupa sinyal PWM dengan frekuensi tinggi. Tabel 2.1 menjelaskan kondisi penyalaan saklar VSI 3 fasa.

\section{B. Pulse Width Modulation}

Tegangan output dari inverter dapat diatur dengan menjalankan kontrol dalam inverter. Metode paling efisien adalah dengan menggunakan pulse width modulation (PWM). Dalam metode ini, input tegangan dc tetap diberikan kepada inverter dan output tegangan ac didapatkan dengan mengatur mati nyala dalam periode tertentu pada inverter menggunakan PWM. Konsep dari Pulse Width Modulation (PWM) adalah memberikan duty cycle yang berbeda-beda di saklar konverter pada frekuensi tinggi untuk memperoleh output tegangan atau arus dengan frekuensi yang diingikan (50 atau $60 \mathrm{~Hz}$ ). Tujuan lainnya adalah untuk mengetahui cara yang paling efektif mengatur proses pensaklaran untuk meminimalisasi distorsi harmonis atau losses pensaklaran [5]. Ketika amplitudo sinyal sinus yang dimodulasi lebih besar dari sinyal segitiga karier, maka akan terjadi over modulasi [6]. Keuntungan dari penggunaan PWM adalah:

a) Kontrol tegangan output dengan metode ini dapat diperoleh tanpa tambahan komponen.

b) Harmonisa lebih mudah untuk dihilangkan atau diminimalisir dengan menggunakan filter harmonisa.

\section{Sinusoidal PWM}

Teknik PWM ini dilakukan dengan cara mengkomparasi sinyal sinus dan sinyal segitiga. Sinyal segitiga ini berfungsi sebagai sinyal karier yang frekuensinya bisa diatur sesuai kebutuhan. Pada VSI 3 fasa, untuk menghasilkan tegangan beban berbeda $120^{\circ}$, dibutuhkan tiga sinyal modulasi yang berbeda $120^{\circ}$ pula [4].

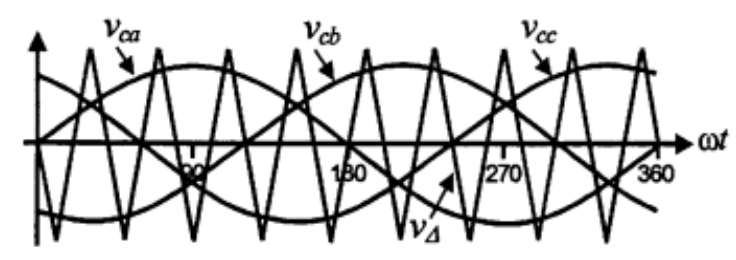

Gambar 3. Sinyal Modulasi dan Sinyal Input 3 Fasa [4]

Gambar 4 memperlihatkan input sinyal tiga fasa dan PWM pada saklar $S_{1}$ dan $S_{3}$. Sinyal tersebut adalah hasil dari proses modulasi dimana sinyal tersebut berbeda sudut $120^{\circ}$.

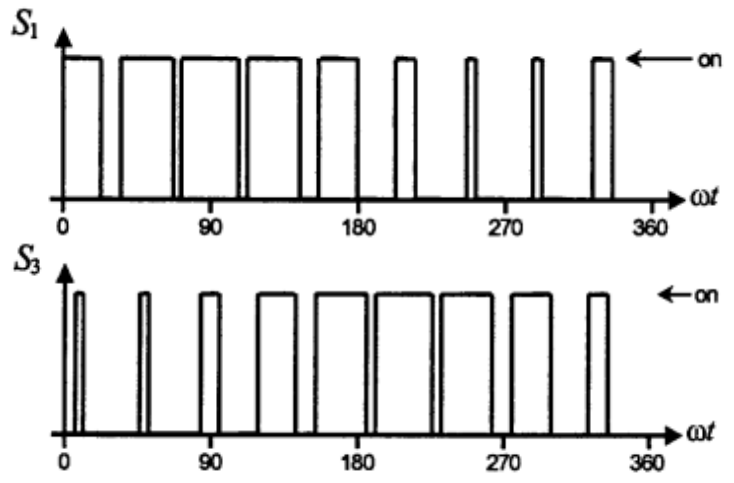

Gambar 4. Input Sinyal PWM $\mathrm{S}_{1}$ dan $\mathrm{S}_{3}[4]$

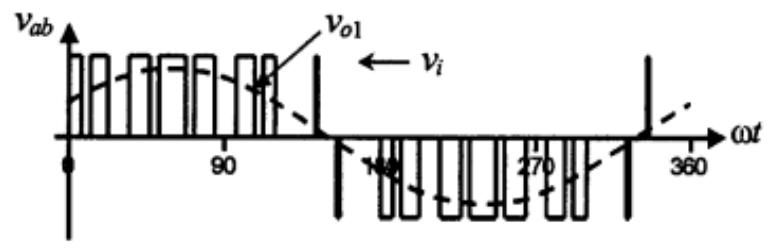

Gambar 5. Sinyal Hasil Inverter PWM pada 1 Fasa [4]

\section{Current Controlled PWM VSI 3 Fasa.}

Curent controlled PWM merupakan salah satu metode yang bisa digunakan untuk mengatur kondisi pensaklaran inverter 3 fasa. Tujuan dari metode ini adalah mengatur arus output inverter mengikuti arus referensi yang diberikan. Pada umumnya teknik current control VSI 3 fasa dapat dibagi menjadi linear control, hysteristis control, predictive control, delta modulation control dan neural-fuzzy control [10]. Dalam tugas akhir ini hanya akan dibahas tentang linear current controlled.

Linear current controlled atau dapat juga disebut dengan sine-triangle regulator merupakan metode current controlled yang dapat digunakan untuk mengatur arus output dari inverter. Metode kontrol ini menggunakan tiga kontroller PI yang digunakan pada masing-masing fasa. Prinsip sederhana dari metode kontrol ini adalah membandingkan sinyal referensi dengan sinyal terukur output inverter. Kemudian akan menghasilkan suatu sinyal output kontroller PI yang akan dimodulasikan dengan sinyal segitiga. Hasil modulasi tersebut akan digunakan untuk pensaklaran pada inverter 3 fasa.

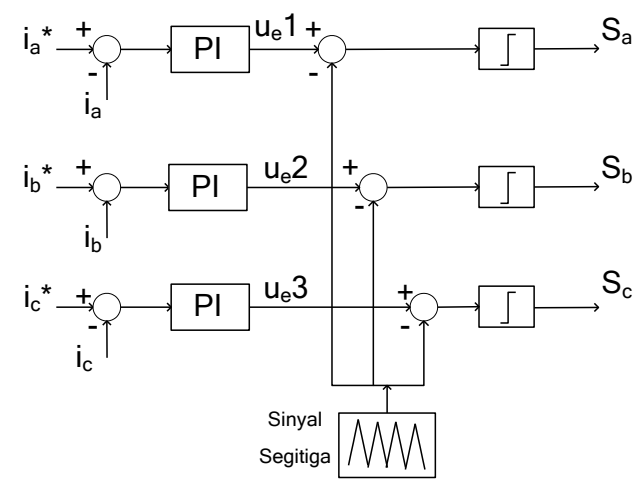

Gambar 6. Linear Current Controlled PWM 
Gambar 6 di atas menunjukkan salah satu metode current controlled yang digunakan untuk mengatur pensaklaran dari inverter. Arus output dari inverter akan mengikuti besarnya arus referensi yang diberikan.

Hasil dari modulasi sinyal output PI kontroller dengan sinyal segitiga berupa sinyal PWM yang digunakan untuk pensaklaran VSI. $S_{a}$ adalah PWM sinyal pensaklaran untuk $\mathrm{S}_{1}$ dan $\mathrm{S}_{4}, \mathrm{~S}_{\mathrm{b}}$ PWM sinyal pensaklaran untuk $\mathrm{S}_{3}$ dan $\mathrm{S}_{6}, \mathrm{~S}_{\mathrm{c}}$ adalah PWM sinyal pensaklaran untuk $S_{2}$ dan $S_{5}$.

\section{E. Voltage Source Current Controlled PWM}

Voltage source current controlled PWM yaitu proses dimana sinyal PWM dibangkitkan oleh sinyal referensi dari tegangan terminal. Tujuan dari kontrol ini adalah menjaga tegangan di terminal sistem konstan dengan cara mengontrol arus output inverter. Metode kontrol konverter digambarkan sebagai berikut:

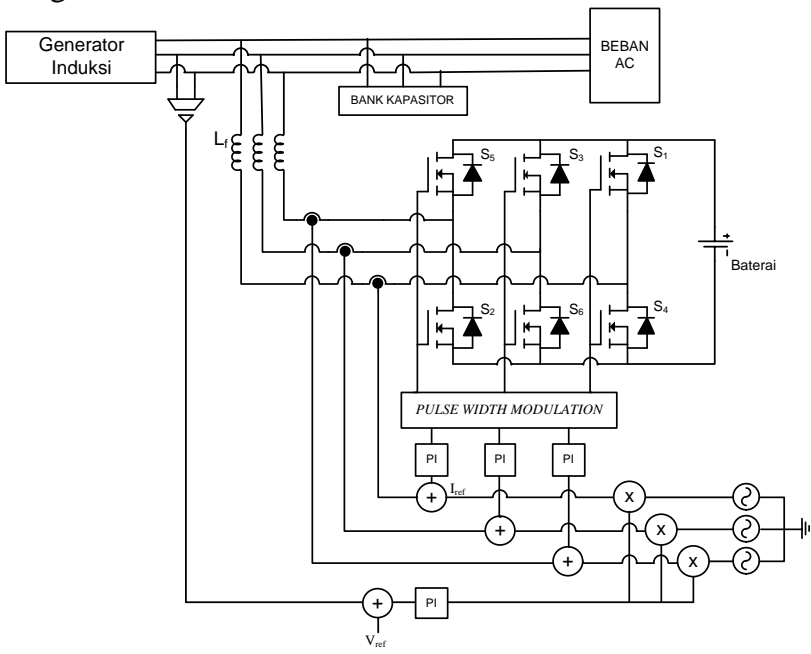

Gambar 7. Voltage Source Current-Controlled PWM Inverter [7]

Fungsi dari sistem kontrol ini adalah untuk mengatur aliran daya aktif dimana sisi DC konstan karena berupa baterai. Jika daya generator melebihi kebutuhan beban, maka daya sisa akan mengalir ke inverter dan disimpan di dalam baterai. Jika beban lebih besar dari kapasitas generator, maka baterai akan ikut menyuplai daya ke beban. Hal ini dilakukan dengan metode current-controlled, sehingga didapatkan sinyal berupa sinusoidal pulse width modulation (SPWM). Sinyal tersebut kemudian digunakan pada IGBT/MOSFET pada konverter.

\section{DESAIN DAN IMPLEMENTASI}

\section{A. Desain Sistem}

Untuk mengatur output generator induksi dapat menggunakan rangkaian VSI. Desain rangkaian VSI yang dimodelkan dengan program simulasi dapat dilihat pada Gambar 8.

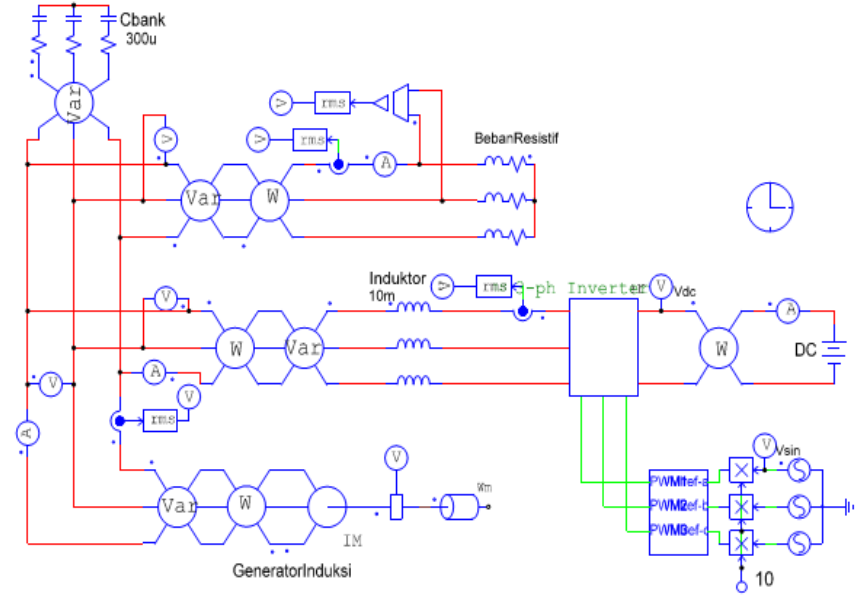

Gambar 8. Desain Sistem

Fungsi dari rangkaian VSI adalah menghasilkan arus reaktif yang digunakan untuk membangkitkan medan magnet pada rotor generator induksi. Besarnya arus yang dikeluarkan VSI bergantung pada metode switching VSI. Dengan mengatur besarnya arus reaktif yang mengalir dapat diatur tegangan output generator induksi. Frekuensi output generator induksi akan mengikuti frekuensi switching VSI 3 fasa yang diatur konstan $50 \mathrm{~Hz}$.

Tujuan utama pemasangan rangkaian VSI pada pengoperasian generator induksi adalah untuk mengatur tegangan dan frekuensi output generator induksi konstan. Hal ini dilakukan dengan cara mengoperasikan generator induksi dengan daya output yang konstan. Daya output generator induksi dapat dialirkan ke beban dan dapat diserap rangkaian VSI. Daya aktif yang dihasilkan generator induksi dapat dirumuskan:

$P_{\text {gen }}=P_{\text {beban }}+P_{i n v}$

$P_{\text {gen }} \quad=$ Daya aktif yang dihasilkan generator

$P_{i n v} \quad=$ Daya aktif yang diserap inverter

$P_{\text {beban }} \quad$ = Daya yang disalurkan ke beban.

Apabila terjadi pengurangan beban, rangkaian VSI akan menyerap daya yang tidak dialirkan ke beban. Pada sisi dc VSI dipasang baterai yang digunakan untuk penyerapan daya inverter.

Untuk menganalisis rangkaian VSI tersebut dilakukan pemodelan terhadap masing-masing komponen pada Gambar 8. Komponen-komponen yang diimplementasikan adalah inverter tiga fasa dan pembangkit sinyal SPWM untuk current-controlled.

\section{B. Parameter Generator Induksi}

Mesin induksi yang digunakan sebagai referensi adalah mesin induksi yang ada di laboratorium dengan spesifikasi peralatan sebagai berikut [8] : 
Tabel 1.

Parameter Mesin Induksi

\begin{tabular}{cc}
\hline \hline Parameter & Nilai \\
\hline$R_{I}$ & $1,0297 \Omega$ \\
$X_{2}$ & $1,02 \Omega$ \\
$R_{2}$ & $0,4973 \Omega$ \\
$X_{2}$ & $1,02 \Omega$ \\
$X_{M}$ & $12,3771 \Omega$ \\
$V_{T H}$ & $51,584 \mathrm{~V}$ \\
$R_{T H}$ & $0,879 \Omega$ \\
$X_{T H}$ & $1,02 \Omega$ \\
$S_{\max }$ & $22,39 \%$ \\
$\tau_{\max }$ & $8,19257 \mathrm{~N} . \mathrm{m}$ \\
$\tau_{\text {ind }}$ & $5,46542 \mathrm{~N} . \mathrm{m}$ \\
$\tau_{\text {start }}$ & $4,1716 \mathrm{~N} . \mathrm{m}$ \\
\hline \hline
\end{tabular}

Parameter-parameter tersebut akan disesuaikan dengan kebutuhan data pada simulasi mesin induksi dan implementasi CC-VSI.

\section{Model Implementasi Sistem}

Dalam implementasi, pengujian yang dilakukan adalah dengan metode open loop. VSI dalam implementasi terdiri dari inverter, driver, dan mikrokontroller untuk membangkitkan sinyal SPWM. Rangkaian yang digunakan dalam sistem ini dapat dilihat pada gambar 9.

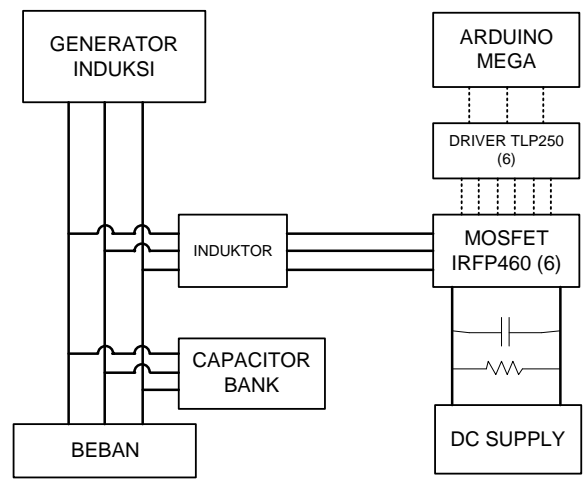

Gambar 9. Model Implementasi Sistem

Pada implementasi terdapat resistor dan kapsitor pada sisi DC. Hal tersebut dikarenakan saat implementasi alat tidak menggunakan baterai melainkan menggunakan DC supply. Resistor dan kapasitor pada sisi DC berguna untuk menghambat arus masuk ke DC supply agar tidak rusak. Gambar 9 di atas menunjukkan rangkaian inverter 3 fasa ini terdiri dari 3 lengan dengan 6 saklar. Kondisi pensaklaran pada VSI ini diatur dengan metode linear current controlled PWM yang dibangkitkan oleh mikrokontroller.

\section{Implementasi VSI}

Implementasi dilakukan untuk mengetahui kinerja inverter berdasarkan desain dan simulasi. Komponen yang digunakan dalam implementasi:

Tabel 2.

Komponen Implementasi CC-VSI

\begin{tabular}{ll}
\hline \multicolumn{2}{c}{ Komponen Implementasi CC-VSI } \\
\hline Komponen & Spesifikasi \\
\hline Mikrokontroler & Arduino Mega 2560 \\
MOSFET & IRFP460 \\
Induktor & $10 \mathrm{mH}$ \\
Bank Kapasitor & $300 \mathrm{uF}$ \\
Beban R & $5 \mathrm{ohm}$ \\
\hline \hline
\end{tabular}

Gambar 10 merupakan implementasi voltage source inverter yang dapat difungsikan secara bidirectional:

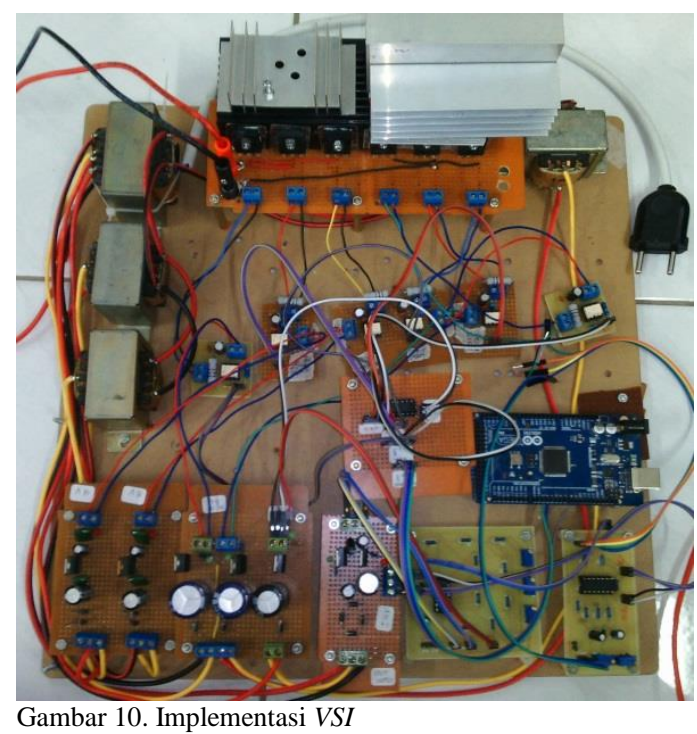

\section{PENGUJIAN}

\section{A. Pengujian Sinyal SPWM}

Pengujian sinyal SPWM dilakukan agar saat sinyal digunakan untuk men-trigger MOSFET tidak terjadi kesalahan. Pengujian dilakukan dengan menggunakan osiloskop digital. Sinyal yang diamati adalah sinyal SPWM output mikrokontroler, sinyal output driver, dan sinyal hasil inverting.

Sinyal SPWM dihasilkan oleh Arduino sebagai mikrokontroler. Frekuensi sinyal SPWM yang digunakan adalah sebesar $3.9 \mathrm{kHz}$ diambil dari prescaler yang ada pada Arduino. Frekuensi untuk output inverter juga dapat diatur di dalam kode Arduino.

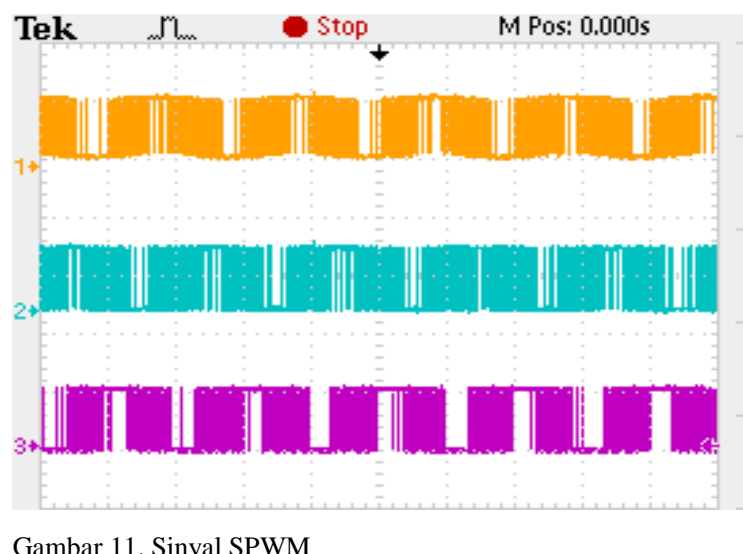

Dari tiga buah sinyal SPWM tersebut, dibuat menjadi enam buah sinyal dan tiga diantaranya dimasukkan ke gerbang NOT untuk diinverting. Proses inverting yaitu mengubah nilai PWM dari on menjadi off dan sebaliknya. 


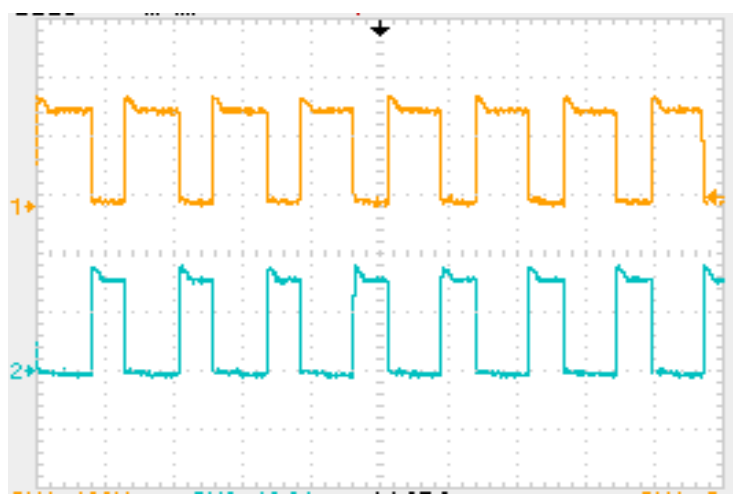

Gambar 12. Output Inverting SPWM

Enam sinyal tersebut kemudian masuk ke rangkaian driver untuk dinaikkan tegangannya agar dapat men-trigger MOSFET. Sinyal yang tidak diinverting masuk ke MOSFET 1, 3, dan 5. Sedangkan sinyal yang diinverting masuk ke MOSFET 2, 4, dan 6. Sinyal ini dibentuk Arduino dengan cara memanggil tabel angka pada kode. Tabel angka tersebut membentuk jajaran duty cycle sehingga terbentuklah sinyal PWM.

\section{B. Pengujian CC-VSI Tanpa Beban}

Pengujian ini dilakukan untuk melihat performa inverter tiga fasa. Pengujian tanpa beban dengan memberikan input DC ke dalam inverter dan melihat bentuk gelombang tegangan yang dihasilkan. Berikut adalah bentuk gelombang tegangan line-to-line pada inverter pada tegangan input DC 10 volt dan indeks modulasi 1 .

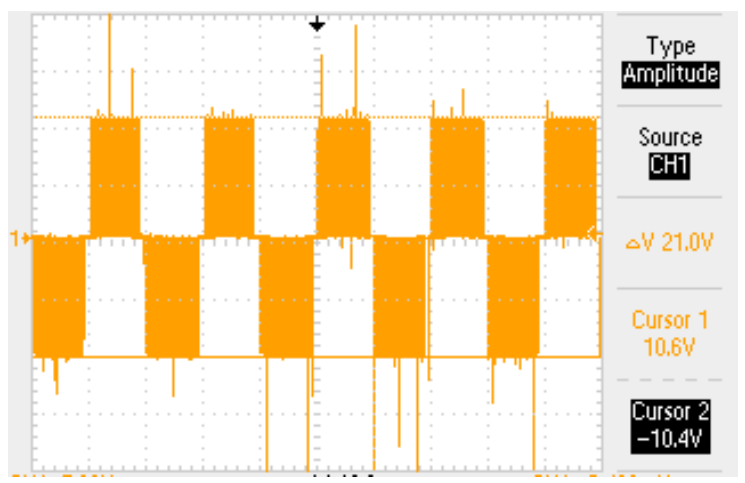

Gambar 13. Gelombang Tegangan Output Inverter

Nilai tegangan peak-to-peak pada Gambar 13 adalah $21 \mathrm{~V}$, maka nilai rmsnya adalah:

$$
V_{r m s}=\frac{V_{P P}}{2 \sqrt{2}}=\frac{21}{2 \sqrt{2}}=7.424 \mathrm{~V}
$$

Nilai tersebut dapat dibuktikan melalui persamaan tegangan output inverter. Tegangan output inverter dipengaruhi oleh tegangan dc input dan indeks modulasi dari sinyal SPWM. Maka, nilai tegangan line-to-line output inverter dapat dihitung dengan persamaan berikut.

$$
V_{L L(r m s)}=m \frac{\sqrt{3}}{2 \sqrt{2}} \cdot V_{D C}=1 \cdot \frac{\sqrt{3}}{2 \sqrt{2}} \cdot 10=6.123 \mathrm{~V}
$$

Hasil pengujian lebih besar dibandingkan dengan hasil perhitungan. Adanya kenaikan tegangan akibat proses pensaklaran yang tidak sempurna karena adanya spike gelombang. Pengujian juga dilakukan dengan mengubah nilai frekuensi input sinyal referensi. Sinyal frekuensi yang diberikan adalah $50 \mathrm{~Hz}$ dan $60 \mathrm{~Hz}$. Berikut adalah hasil pengujian saat mengubah nilai frekuensi:

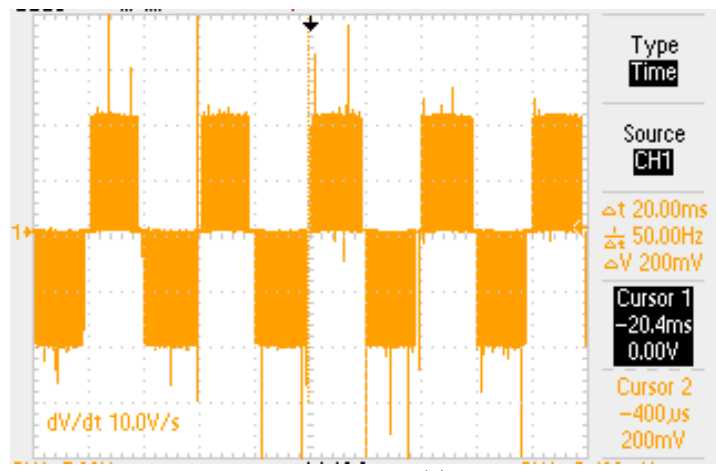

(a)

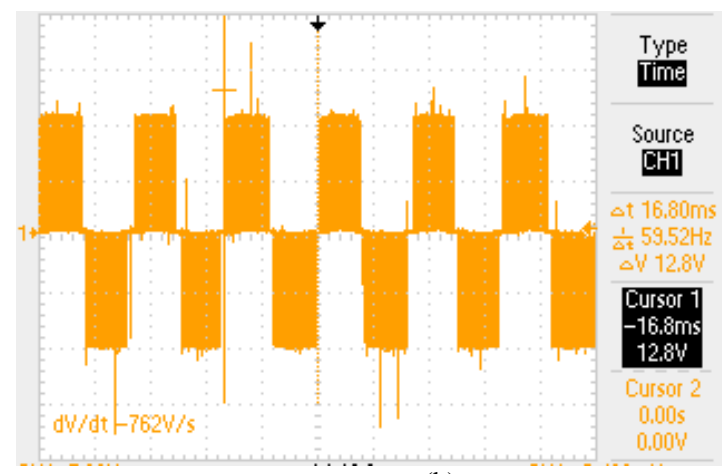

(b)

Gambar 14. Gelombang Tegangan Output Inverter: (a) Frekuensi 50Hz; (b) Frekuensi $60 \mathrm{~Hz}$

Frekuensi yang dapat diatur pada mikrokontroler adalah frekuensi SPWM dan frekuensi per cyclenya. Frekuensi SPWM akan mempengaruhi kecepatan pensaklaran pada MOSFET. Hal tersebut akan berpengaruh ke bentuk gelombang output dari inverter. Semakin besar kecepatan pensaklaran, maka akan semakin halus bentuk gelombang yang dihasilkan. Sedangkan untuk frekuensi cycle SPWM akan berpengaruh ke frekuensi output AC.

\section{Pengujian CC-VSI Beban Resistif}

Selanjutnya adalah pengujian inverter dengan beban resistif. Beban yang digunakan adalah 3 buah Rheostat dengan resistansi $10 \mathrm{ohm}$. Pengujian ini dilakukan untuk melihat bentuk gelombang tegangan dan arus output inverter. Pengujian ini dilakukan dalam dua kondisi yaitu dengan filter $\mathrm{L}$ dan filter LC. Induktor sebagai filter arus dipasang seri pada output inverter. Kapasitor sebagai filter tegangan dipasang paralel dan dikoneksikan wye.

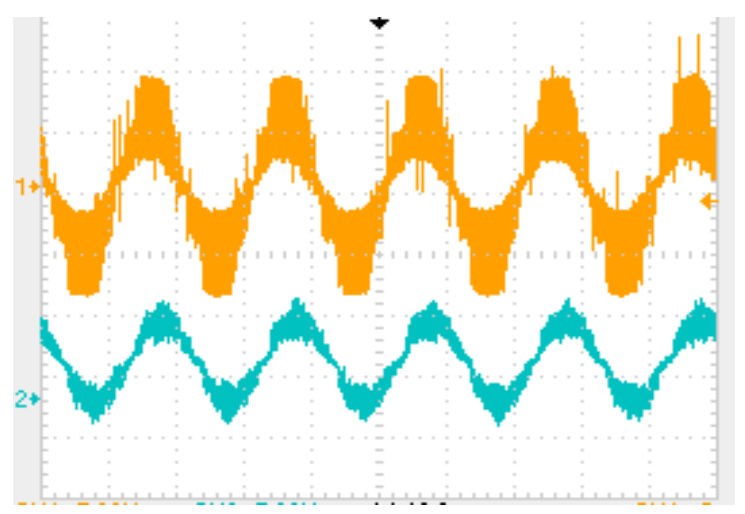

Gambar 15. Gelombang Output Inverter dengan Filter L 
Induktor dipasang seri di sisi ouput inverter. Fungsi induktor adalah sebagai filter arus masuk ke terminal sistem. Nilai induktor yang digunakan adalah $10 \mathrm{mH}$. Nilai tersebut diperoleh melalui hubungan antara tegangan line, tegangan dc, dan daya pada sistem.

$$
\begin{aligned}
& X_{L}=\frac{\sqrt{3} \cdot V_{d c} \cdot V_{L}}{2 \cdot P}=\frac{\sqrt{3} \cdot 138 \cdot 106}{2 \cdot 417}=30,379 \mathrm{ohm} \\
& L=\frac{X_{L}}{\omega}=\frac{30,379}{2 \pi \cdot 50}=0.0967 \mathrm{H}
\end{aligned}
$$

Didapatkan nilai induktor sebesar $9.67 \mathrm{mH}$. Nilai $\mathrm{V}_{\mathrm{DC}}, \mathrm{V}_{\mathrm{L}}$, dan $\mathrm{P}$ diperoleh dari simulasi sistem dan nilai induktor tersebut dapat digunakan pada program simulasi. Tetapi pada implementasi, nilai belitan induktor adalah $10 \mathrm{mH}$. Hal tersebut dikarenakan belitan induktor tidak bisa sama dengan nilai tersebut dan nilai yang digunakan adalah nilai yang dekat tetapi lebih besar.

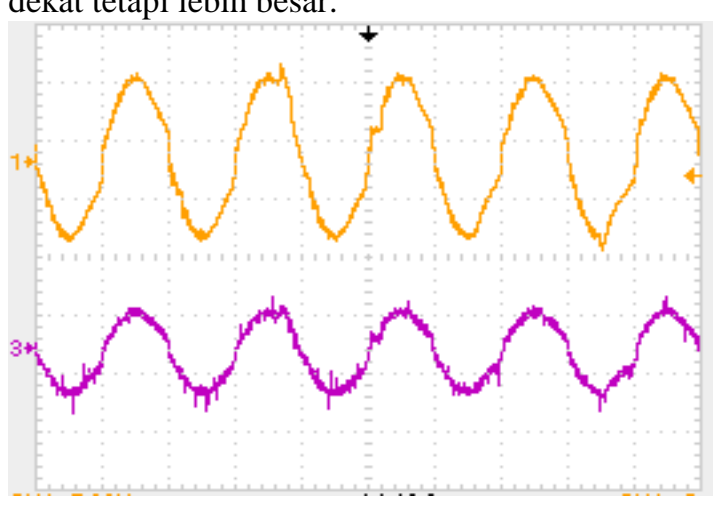

Gambar 16. Gelombang Output Inverter dengan Filter LC

Fungsi kapasitor adalah sebagai filter tegangan dan membantu inverter untuk menyuplai daya reaktif ke generator saat dibutuhkan. Nilai kapasitor yang digunakan adalah 300uF. Nilai tersebut didapatkan dari perhitungan dengan nilai reaktansi magnetisasi generator.

$$
\begin{aligned}
& X_{M}=X_{C}=12.3771 \\
& C=\frac{1}{\omega \cdot X_{C}}=\frac{1}{2 \pi \cdot 50 \cdot 12.3771}=257.176 \mu \mathrm{F}
\end{aligned}
$$

Nilai tersebut merupakan nilai kapasitansi minimal yang dibutuhkan generator untuk dapat eksitasi pada sistem generator induksi eksitasi sendiri. Tetapi pada implementasi kapasitor berfungsi untuk filter dan penyuplai eksitasi tambahan dikarenakan eksitasi utama sistem adalah dari inverter.

\section{Pengujian CC-VSI dan Generator dengan Perubahan Kecepatan}

Generator induksi adalah mesin induksi yang dikopel dengan mesin induksi lain yang dikontrol dengan menggunakan variable frequency drive (VFD) untuk mengatur kecepatan putaran mesin. Mesin diputar melebihi kecepatan sinkronnya yaitu $1500 \mathrm{rpm}$ yang didapatkan dengan perhitungan sebagai berikut:

$$
\begin{aligned}
n_{\text {sync }} & =\frac{120 f}{p} \\
n_{\text {sync }} & =\frac{120(50)}{4} \\
n_{\text {sync }} & =1500 \mathrm{rpm}
\end{aligned}
$$

Oleh karena itu mesin diputar di atas kecepatan sinkronnya agar mesin dapat beroperasi sebagai generator. Jika mesin diputar semakin cepat, maka slip akan membesar sehingga memperbesar torsi mesin. Hal tersebut menyebabkan daya yang dihasilkan generator juga akan bertambah besar.

Pengujian ini dilakukan untuk mengetahui aliran daya generator dan inverter. Pada pengujian ini, yang menjadi variable adalah kecepatan putar mesin. Cara pengujian yaitu pertama dengan memutar mesin sampai pada kecepatan sinkronnya. Kemudian memasukkan input tegangan DC pada inverter untuk memberikan eksitasi pada generator induksi. Tegangan yang digunakan untuk pengujian adalah $15 \mathrm{~V}, 20 \mathrm{~V}$, $30 \mathrm{~V}$, 40V, dan 50V. Setelah tegangan DC dimasukkan, kecepatan dinaikkan dengan mengatur frekuensi pada VFD untuk melihat aliran daya generator dan inverter. Frekuensi VFD yang digunakan untuk pengujian adalah $50 \mathrm{~Hz}, 51 \mathrm{~Hz}$, $52 \mathrm{~Hz}, 53 \mathrm{~Hz}, 54 \mathrm{~Hz}$, dan $55 \mathrm{~Hz}$. Beban yang digunakan dibuat besar yaitu Rheostat tiga fasa $5 \mathrm{ohm}$ agar sebagian besar daya mengalir ke arah beban. Berikut adalah tabel hasil pengujian:

Tabel 3.

(a) Pengujian Aliran Daya Tegangan 15V, (b) Pengujian Aliran Daya Tegangan 20V, (c) Pengujian Aliran Daya Tegangan 30V, (d) Pengujian Aliran Daya Tegangan 40V dan (e) Pengujian Aliran Daya Tegangan 50V

\begin{tabular}{cccccc} 
Frekuensi & Kecepatan & $\mathbf{V}_{\mathbf{D C}}$ & $\mathbf{I}_{\mathbf{D C}}$ & $\mathbf{V}_{\mathbf{A C}}$ & $\mathbf{I}_{\mathbf{I N V}}$ \\
\hline 50 & 1489.7 & 15 & 1.23 & 6.5 & 1 \\
51 & 1522.5 & 15 & 0.83 & 7.06 & 0.78 \\
52 & 1548.7 & 15 & 0.6 & 7.63 & 0.65 \\
53 & 1580.3 & 15 & 0.44 & 8.21 & 0.66 \\
54 & 1611 & 15.2 & 0.37 & 9.23 & 0.98 \\
55 & 1638.2 & 19.7 & 0.44 & 13.3 & 1.94 \\
\hline \hline & & $(\mathrm{a})$ & & & \\
\hline \hline Frekuensi & Kecepatan & $\mathbf{V}$ & & & \\
\hline 50 & 1489.7 & 20 & 1.7 & 10 & 1.47 \\
51 & 1522.5 & 20 & 1.33 & 10.5 & 1.09 \\
52 & 1548.7 & 20 & 0.9 & 10.98 & 0.86 \\
53 & 1580.3 & 20 & 0.48 & 11.49 & 0.88 \\
54 & 1611 & 20 & 0.14 & 11.91 & 1.21 \\
55 & 1638.2 & 24.7 & 0.01 & 15.38 & 1.88 \\
\hline \hline
\end{tabular}

\begin{tabular}{cccccc}
\hline \hline Frekuensi & Kecepatan & $\mathbf{V}_{\mathbf{D C}}$ & $\mathbf{I}_{\mathbf{D C}}$ & $\mathbf{V}_{\mathbf{A C}}$ & $\mathbf{I}_{\mathbf{I N V}}$ \\
\hline 50 & 1489.7 & 30 & 2.74 & 15.4 & 2.28 \\
51 & 1522.5 & 30 & 2.12 & 15.94 & 1.76 \\
52 & 1548.7 & 30 & 1.5 & 16.62 & 1.37 \\
53 & 1580.3 & 30 & 1 & 17.24 & 1.28 \\
54 & 1611 & 30 & 0.6 & 17.64 & 1.47 \\
55 & 1638.2 & 30 & 0.2 & 18.09 & 1.93 \\
\hline \hline
\end{tabular}

(c) 


\begin{tabular}{cccccc}
\hline \hline Frekuensi & Kecepatan & $\mathbf{V}_{\mathbf{D C}}$ & $\mathbf{I}_{\mathbf{D C}}$ & $\mathbf{V}_{\mathbf{A C}}$ & $\mathbf{I}_{\mathbf{I N V}}$ \\
\hline 50 & 1489.7 & 40 & 3.7 & 20.64 & 3.02 \\
51 & 1522.5 & 40 & 2.9 & 21.33 & 2.4 \\
52 & 1548.7 & 40 & 2.3 & 22 & 2 \\
53 & 1580.3 & 40 & 1.7 & 22.6 & 1.76 \\
54 & 1611 & 40 & 1.32 & 23.04 & 1.8 \\
55 & 1638.2 & 40 & 0.82 & 23.64 & 2.07 \\
\hline \hline
\end{tabular}

\begin{tabular}{cccccc}
\hline \hline Frekuensi & Kecepatan & $\mathbf{V}_{\mathbf{D C}}$ & $\mathbf{I}_{\mathbf{D C}}$ & $\mathbf{V}_{\mathbf{A C}}$ & $\mathbf{I}_{\mathbf{I N V}}$ \\
\hline 50 & 1489.7 & 50 & 4.6 & 25.63 & 3.71 \\
51 & 1522.5 & 50 & 3.88 & 26.14 & 3.17 \\
52 & 1548.7 & 50 & 3.21 & 27.08 & 2.7 \\
53 & 1580.3 & 50 & 2.71 & 27.86 & 2.44 \\
54 & 1611 & 50 & 2.2 & 28.5 & 2.28 \\
55 & 1638.2 & 50 & 1.86 & 28.6 & 2.36 \\
\hline \hline \multicolumn{5}{c}{ (e) }
\end{tabular}

Dari hasil pengujian dapat dilihat bahwa semakin besar kecepatan yang diberikan ke generator, arus di sisi dc semakin turun pada tegangan yang tetap. Hal tersebut dikarenakan semakin cepat putaran, semakin besar daya yang dihasilkan generator sehingga aliran daya dari inverter ke beban berkurang. Gambar 17 memperlihatkan hasil simulasi aliran daya saat diubah kecepatan generator.

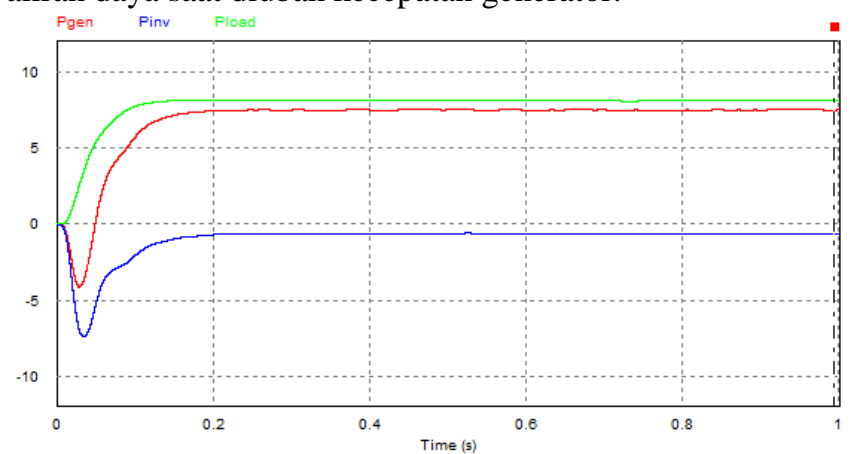

(a)

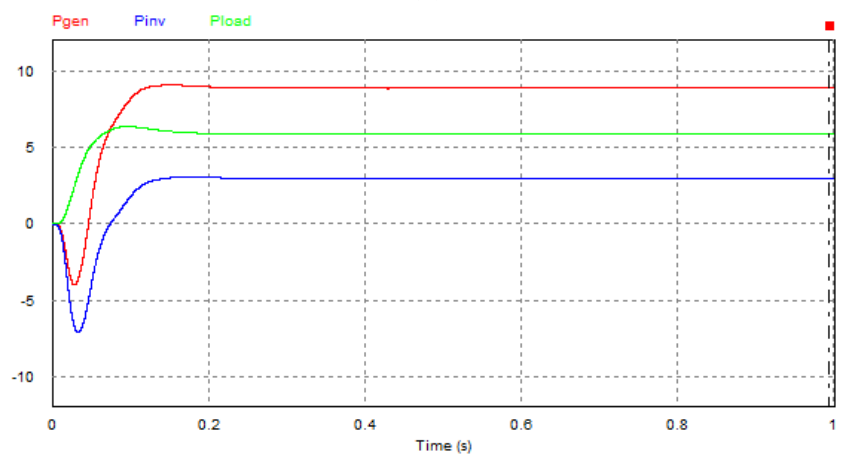

(b)

Gambar 17. Simulasi Perubahan Kecepatan Generator Induksi: (a) 1580.3 rpm; (b) $1638.2 \mathrm{rpm}$

Gambar 17 memperlihatkan hasil simulasi saat kecepatan generator dinaikkan. Daya pada sistem dijaga konstan oleh CC-VSI sehingga saat daya generator melebihi daya yang dibutuhkan beban, daya yang masuk inverter meningkat.

Analisis selanjutnya adalah pada Tabel 4.1 (a) dan (b) terdapat sedikit perubahan tegangan suplai dc. Misalkan pada data tegangan $15 \mathrm{~V}$ dengan frekuensi $55 \mathrm{~Hz}$ tegangan dc berubah menjadi $19.7 \mathrm{~V}$. Hal tersebut dikarenakan adanya kenaikan tegangan sistem yang melebihi tegangan line-toline pada indeks modulasi sinyal SPWM yang bernilai 1 . Permasalahan tersebut dapat dibuktikan dengan perhitungan berikut:

$$
m=\frac{2 \sqrt{2} \cdot V_{L L}}{\sqrt{3} \cdot V_{D C}}=\frac{2 \sqrt{2} \cdot 13.3}{\sqrt{3} \cdot 15}=1.447
$$

Pada tegangan sistem 9.64V nilai indeks modulasinya melebihi nilai dari indeks modulasi pensaklaran inverter. Hal tersebutlah yang menyebabkan kenaikan tegangan di sisi dc mengikuti tegangan ac.

Pada Tabel 4.1 arus inverter mengalami perubahan dari turun menjadi naik. Nilai ini didapatkan dari pengukuran menggunakan amperemeter digital. Nilai tersebut merupakan nilai total arus yaitu arus aktif dan arus reaktif. Hal tersebut disebabkan karena saat kecepatan generator 1580.3 - 1638.2 rpm, inverter dalam kondisi disuplai generator. Maka arus tersebut adalah aus yang menuju ke inverter.

\section{E. Pengujian Aliran Daya Reaktif Generator}

Daya reaktif terbentuk karena arus yang mendahului tegangan atau yang biasa disebut dengan leading. Daya reaktif diperlukan oleh mesin induksi untuk eksitasi agar dapat berfungsi sebagai generator. Pada pengujian ini data yang paling penting adalah sudut daya yang digunakan untuk menentukan faktor daya. Faktor daya menentukan berapa besar daya dan kemana daya itu mengalir. Gambar 18 (a) merupakan perbandingan antara tegangan dan arus output generator saat dioperasikan pada kecepatan $1548.7 \mathrm{rpm}$ Sedangkan pada Gambar 18 (b) merupakan tegangan dan arus menuju ke arah beban.

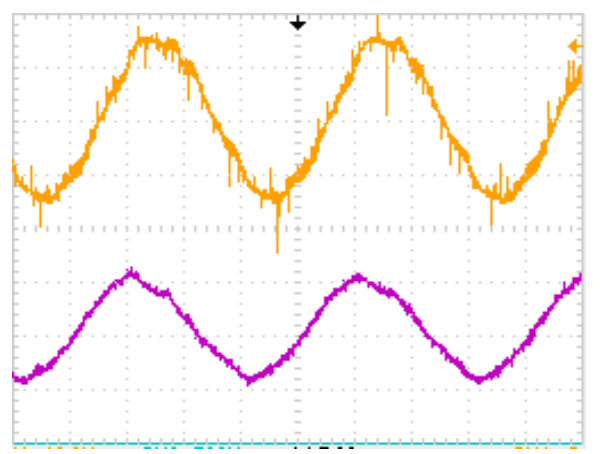

(a)

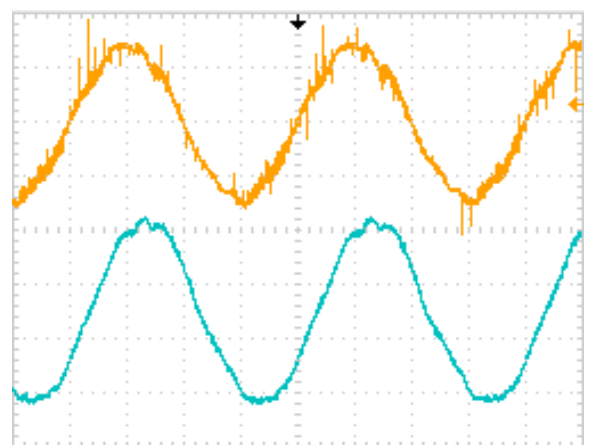

(b)

Gambar 18. Pengujian pada Tegangan $20 \mathrm{~V}_{\mathrm{DC}}$ : (a) Tegangan dan Arus Generator; (b) Tegangan dan Arus Beban

Nilai sudut daya pada Gambar 18 (a) dinamakan lagging yang berarti bersifat induktif. Sedangkan pada Gambar 18 (b) 
dinamakan leading yang berarti bersifat kapasitif. Sifat-sifat tersebut biasanya dipengaruhi oleh beban atau komponen yang ada, seperti kapasitor atau induktor. Untuk menentukan daya reaktif diperlukan sudut daya tersebut. Maka dari itu dilakukan perhitungan daya reaktif pada pengujian yang direpresentasikan pada tabel berikut:

Tabel 4.

Data Pengujian Daya Reaktif pada Tegangan 20V

\begin{tabular}{lllll}
\hline \hline Titik Pengamatan & $\begin{array}{l}\text { Tegangan } \\
(\mathbf{V})\end{array}$ & $\begin{array}{l}\text { Arus } \\
(\mathbf{A})\end{array}$ & Sin $\boldsymbol{\theta}$ & $\begin{array}{l}\text { Daya } \\
\text { Reaktif } \\
\text { (VAR) }\end{array}$ \\
\hline & 10 & 1.03 & -0.996 & -10.260 \\
GENERATOR & 10.5 & 1.14 & -0.766 & -9.175 \\
& 10.98 & 1.45 & -0.622 & -9.907 \\
& 11.49 & 1.94 & -0.431 & -9.617 \\
& 11.91 & 2.46 & -0.326 & -9.548 \\
INVERTER & 15.38 & 3.46 & -0.303 & -16.099 \\
& 10 & 1.47 & 0.420 & 6.171 \\
& 10.5 & 1.09 & 0.592 & 6.774 \\
& 10.98 & 0.86 & 0.902 & 8.519 \\
& 11.49 & 0.88 & 0.951 & 9.616 \\
KAPASITOR & 11.91 & 1.21 & 0.798 & 11.494 \\
& 15.38 & 1.88 & 0.588 & 16.995 \\
& 10 & 1.32 & -0.962 & -12.733 \\
& 10.5 & 1.15 & -0.941 & -11.404 \\
& 10.98 & 1.05 & -0.904 & -10.426 \\
& 11.49 & 1.05 & -0.930 & -11.217 \\
& 11.91 & 1.26 & -0.960 & -14.491 \\
& 15.38 & 1.65 & -0.991 & -25.165 \\
& 10 & 1.11 & 0.498 & 5.558 \\
& 10.5 & 1.18 & 0.572 & 7.141 \\
& 10.98 & 1.23 & 0.524 & 7.111 \\
& 11.49 & 1.28 & 0.465 & 6.878 \\
& 11.91 & 1.34 & 0.453 & 7.265 \\
& 15.38 & 1.74 & 0.464 & 12.437 \\
\hline
\end{tabular}

Tabel 4 adalah tabel hasil pengujian pada semua bagian bercabang pada sistem dengan enam sampel pada kecepatan generator yang berbeda seperti data sebelumnya. Daya reaktif $\mathrm{Q}$ didapatkan melalui perkalian antara tegangan line-to-line, arus belitan, dan $\sin \theta$. Daya reaktif yang terbangkit pada sistem merupakan penjumlahan dari daya reaktif kapasitor dan dari inverter. Sedangkan pada sisi generator dan beban teraliri daya reaktif. Simulasi digunakan untuk dibandingkan dengan hasil pengujian pada kecepatan generator $1638.2 \mathrm{rpm}$.

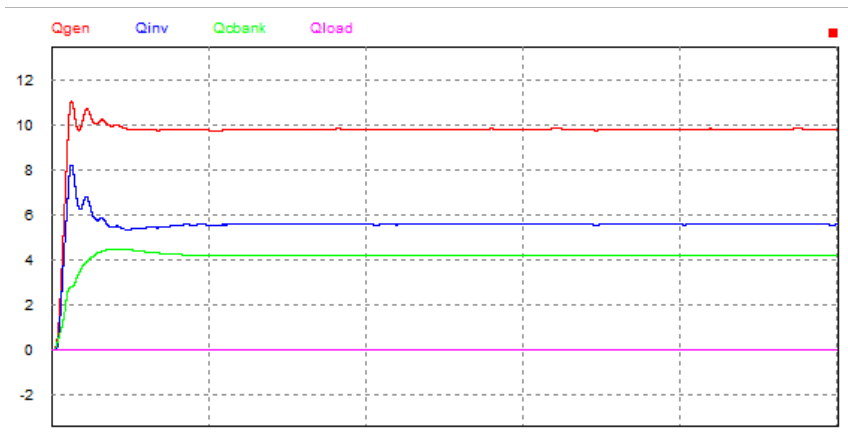

Gambar 19. Simulasi Aliran Daya Reaktif

Dari Gambar 19 dapat dilihat bahwa aliran daya reaktif adalah menuju generator yang disuplai dari inverter dan bank kapasitor, sedangkan beban tidak ada aliran daya reaktif karena beban bersifat resistif. Generator menyerap daya reaktif besar saat putaran generator ditambah untuk menghasilkan daya yang besar. Pada implementasi terdapat aliran daya reaktif ke beban dikarenakan sifat beban tidak resistif murni.

\section{F. Pengujian Aliran Daya Aktif Generator}

Pengujian aliran daya aktif dapat diperoleh melalui perhitungan dari data tegangan, arus, dan faktor daya pada masing-masing percabangan sistem. Diambil enam data pada masing-masing percabangan sistem. Enam data tersebut diukur pada kecepatan yang berbeda seperti pada Tabel 4. Tabel 5 menjabarkan data yang diperoleh dari pengujian pada tegangan $20 \mathrm{~V}$ di empat titik pengamatan.

Tabel 5.

Data Pengujian Daya Aktif pada Tegangan 20V

\begin{tabular}{lllll}
\hline \hline $\begin{array}{l}\text { Titik } \\
\text { Pengamatan }\end{array}$ & $\begin{array}{l}\text { Tegangan } \\
(\mathbf{V})\end{array}$ & $\begin{array}{l}\text { Arus } \\
(\mathbf{A})\end{array}$ & Cos $\boldsymbol{\theta}$ & $\begin{array}{l}\text { Daya Aktif } \\
(\mathbf{W})\end{array}$ \\
\hline & 10 & 1.03 & 0.088 & 0.905 \\
& 10.5 & 1.14 & 0.642 & 7.688 \\
GENERATOR & 10.98 & 1.45 & 0.783 & 12.463 \\
& 11.49 & 1.94 & 0.902 & 20.109 \\
& 11.91 & 2.46 & 0.945 & 27.699 \\
& 15.38 & 3.46 & 0.953 & 50.721 \\
& 10 & 1.47 & 0.908 & 13.342 \\
INVERTER & 10.5 & 1.09 & 0.806 & 9.225 \\
& 10.98 & 0.86 & 0.431 & 4.074 \\
& 11.49 & 0.88 & -0.309 & -3.125 \\
& 11.91 & 1.21 & -0.603 & -8.693 \\
& 15.38 & 1.88 & -0.809 & -23.392 \\
& 10 & 1.32 & 0.271 & 3.591 \\
BAPASITOR & 10.5 & 1.15 & 0.338 & 4.097 \\
& 10.98 & 1.05 & 0.427 & 4.922 \\
& 11.49 & 1.05 & 0.368 & 4.441 \\
& 11.91 & 1.26 & 0.279 & 4.210 \\
& 15.38 & 1.65 & 0.134 & 3.393 \\
& 10 & 1.11 & 0.867 & 9.689 \\
& 10.5 & 1.18 & 0.820 & 10.228 \\
& 10.98 & 1.23 & 0.851 & 11.546 \\
& 11.49 & 1.28 & 0.885 & 13.090 \\
& 11.91 & 1.34 & 0.891 & 14.290 \\
& 15.38 & 1.74 & 0.886 & 23.730 \\
\hline
\end{tabular}

Tegangan dan arus dari Tabel 5 diperoleh dari pengukuran menggunakan multimeter. Sedangkan data faktor daya diperoleh dengan membandingkan gelombang pada osiloskop sehingga didapatkan sudut dayanya. Seperti yang telah dijelaskan bahwa semakin cepat putaran generator maka akan semakin besar daya yang dihasilkan. Daya yang telah dihitung dapat dibandingkan dengan membandingkan antara daya yang dihasilkan dan daya yang diserap. Daya yang dihasilkan adalah penjumlahan dari daya generator dan daya inverter yang bernilai positif. Sedangkan daya yang diserap adalah penjumlahan dari daya kapasitor, daya beban, dan daya inverter yang bernilai negatif. Perhitungan tersebut disusun dalam Tabel 8 berikut.

Tabel 6.

Perbandingan Daya Aktif pada Tegangan 20V

\begin{tabular}{cc}
\hline \hline Daya Dihasilkan $(W)$ & Daya Diserap $(\mathbf{W})$ \\
\hline 14.247 & 13.280 \\
16.913 & 14.325 \\
16.538 & 16.468 \\
16.985 & 17.532 \\
19.006 & 18.500 \\
27.329 & 27.124 \\
\hline \hline
\end{tabular}

Dari tabel di atas, terdapat selisih antara daya yang dihasilkan dan daya yang diserap. Selisih tersebut merupakan losses dari sistem yang disebabkan oleh impedansi kabel dan 
losses pensaklaran. Simulasi digunakan untuk dibandingkan dengan hasil pengujian pada kecepatan generator $1638.2 \mathrm{rpm}$.

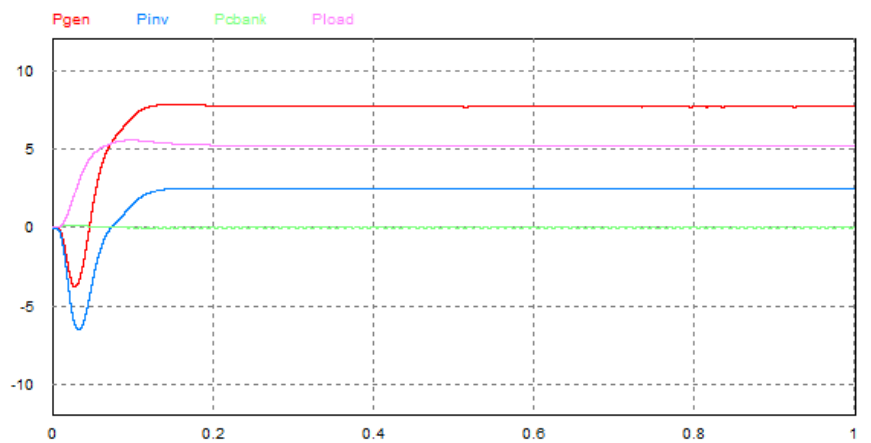

Gambar 20. Simulasi Aliran Daya Aktif

Pada Gambar 20 aliran daya aktif mengalir dari generator menuju beban dan inverter. Daya aktif tidak masuk ke bank kapasitor sedangkan pada implementasi ada daya aktif yang mngalir. Hal tersebut menandakan bahwa kapasitor pada implementasi tidak murni bersifat kapasitif.

\section{KESIMPULAN}

Dari hasil simulasi, implementasi, dan analisis data yang dilakukan dapat ditarik kesimpulan bahwa:

1) Saat mesin induksi beroperasi di atas kecepatan sinkronnya dan diinjek tegangan pada nominal tertentu dari inverter, maka mesin akan beroperasi sebagai generator dan menyerap daya reaktif.

2) Kecepatan generator induksi akan menentukan besar daya yang dihasilkan, sehingga akan berpengaruh pada aliran daya sistem baik daya aktif maupun daya reaktif.

3) Daya pada sistem akan dijaga konstan oleh inverter dengan cara menyerap dan menyuplai daya. Maka dari itu, baterai sebagai media penyimpan sangat cocok digunakan pada sistem yang dapat beroperasi bidirectional.

\section{DAFTAR PUSTAKA}

[1] E. Muljadi and T. A. Lipo, "Series Compensated PWM Inverter with Battery Supply Applied to an Isolated Induction Generator," IEEE Trans., vol. 30, pp. 1073-1082, Juli/Agustus 1994

[2] E. G. Marra and J. A. Pomilio, "Self-Excited Induction Generator Controlled by a VS-PWM Bidirectional Converter for Rural Application," IEEE Trans., vol. 35, pp. 877-883, Juli/Agustus 1999

[3] S. J. Chapman, "Electric Machinery Fundamentals”, Mc Graw-Hill, NY, 2005

[4] M. Rashid, "Power Electronics Handbook”, Academic Press, Calefornia, 2001

[5] M. S. Abu-hamdeh, "Modeling of Bi-directional Converter for Wind Power Generation”, The Ohio State University, 2009

[6] Infineon, "Different PWM Waveforms Generation for 3-Phase AC Induction Motor with XC164CS", Infineon Technologies AG, Munchen, 2006

[7] Jose R. Rodriguez, Juan W. Dixon, Jose R. Espinoza, and Pablo Lezana, "PWM Regenerative Rectifiers: State of the Art", IEEE Trans. Ind. Electron., vol. 52, no. I, pp. 5-22, Feb. 2005.

[8] Q. Muhammad. "Penurunan Rating Tegangan pada Belitan Motor Induksi 3 Fasa dengan Metode Rewinding untuk Aplikasi Kendaraaan Listrik", ITS, Surabaya, 2013. 